\title{
The Attack and Defense of Weakest-Link Networks ${ }^{*}$
}

\author{
Dan Kovenock, ${ }^{a}$ Brian Roberson, ${ }^{b}$ and Roman M. Sheremeta ${ }^{c}$ \\ a Department of Economics, The University of Iowa, \\ W284 John Pappajohn Bus Bldg, Iowa City, IA 52242-1994, USA \\ ${ }^{\mathrm{b}}$ Department of Economics, Krannert School of Management, Purdue University, \\ 403 W. State St, West Lafayette, IN 47906-2056, USA \\ ${ }^{c}$ Argyros School of Business and Economics, Chapman University, \\ One University Drive, Orange, CA 92866, USA
}

September 28, 2010

\begin{abstract}
This paper experimentally examines behavior in a two-player game of attack and defense of a weakest-link network of targets, in which the attacker's objective is to successfully attack at least one target and the defender's objective is diametrically opposed. We apply two benchmark contest success functions (CSFs): the auction CSF and the lottery CSF. Consistent with the theoretical prediction, under the auction CSF, attackers utilize a stochastic "guerilla warfare" strategy - in which a single random target is attacked - more than $80 \%$ of the time. Under the lottery CSF, attackers utilize the stochastic guerilla warfare strategy almost $45 \%$ of the time, contrary to the theoretical prediction of an equal allocation of forces across the targets.
\end{abstract}

JEL Classifications: C72, C91, D72, D74

Keywords: Colonel Blotto, conflict resolution, weakest-link, best-shot, multi-dimensional resource allocation, experiments.

Corresponding author: Roman M. Sheremeta, sheremet@chapman.edu

* We thank Tim Cason, Subhasish M. Chowdhury, Tim Shields, Nat Wilcox, seminar participants at Chapman University and participants at the 2009 Economic Science Association meeting for helpful discussions and comments. We retain responsibility for any errors. 


\section{Introduction}

In many network applications, such as cyber-security, electrical power grids, or oil pipeline systems, the failure of any individual component in the network may be sufficient to disable the entire network. In the case of a system of dikes on the perimeter of an island, Hirshleifer (1983) coined the term weakest-link to describe this particular type of intra-network complementarity among components. ${ }^{1}$ In addition to networks with physically linked components, political considerations may create a situation in which physically disjoint components are connected by a form of weakest-link complementarity in preferences. For example, a single terrorist spectacular may allow a terrorist organization to influence its target audience and cause anti-terrorism policies to be seen as a failure. ${ }^{2}$

This paper experimentally investigates a two-player game of attack and defense of a weakest-link network of targets. In this game a risk neutral attacker and defender simultaneously allocate a scarce resource (forces) obtained at constant unit cost (normalized to one) across the set of targets. Because the destruction of a single target renders the entire network inoperable, the attacker receives a prize of value $v_{A}>0$ if he successfully attacks at least one target. The defender receives a prize of value $v_{D}>0$ if he successfully defends all targets. For each player, the probability of winning any given target is determined by the levels of the resource that the respective players allocate to that target and the contest success function (CSF) that maps the two players' resource allocations into their respective probabilities of winning. We examine two types of contest success functions: the "auction" CSF, in which the player with the greater

\footnotetext{
${ }^{1}$ A number of environments can be described using the weakest-link structure. Kremer (1993) develops a theoretical model in which the performance of an organization depends mainly on the weakest-link. Moore et al. (2009) argue that "fixing online crime is hard because Internet security is often weakest-link". Milgrom (2007) considers an example of a package auction in which the objective of some bidders may be to obtain only one good (weakestlink), if goods are perfect substitutes.

${ }^{2}$ As stated in the Joint House-Senate Intelligence Inquiry into September 11, 2001 (US Congress, 2002), terrorists need to be successful only once to kill Americans and demonstrate the inherent vulnerabilities they face.
} 
allocation to a target wins that target with certainty, and the "lottery" CSF, in which the probability of winning a target equals the ratio of a player's resource allocation to the sum of the players' resource allocations to that target (with randomization independent across targets).

Clark and Konrad (2007) and Kovenock and Roberson (2010a) theoretically analyze this two-player game of attack and defense of a weakest-link network of targets under the lottery and auction CSFs, respectively. ${ }^{3}$ Under the lottery CSF, if $\left(v_{A} / v_{D}\right)$, the ratio of the attacker's valuation of success to the defender's valuation of success, is below a threshold (determined by the number of targets, $n$ ), the defender plays a pure strategy that allocates the same positive level of the resource to each target. If this ratio of valuations exceeds the threshold then the defending player optimally mixes between allocating none of the resource to defense and allocating the same positive level of the resource to each target. However, for all parameter configurations the attacker plays a pure strategy that allocates an identical strictly positive level of the resource to each target. Under the auction CSF, the theoretical predictions are fundamentally different. In all equilibria the attacker utilizes a "stochastic guerilla warfare strategy" in which, with probability one, at most one single target is attacked, but each of the targets is chosen with equal probability to be the target attacked. The optimal strategy for the defender is to "stochastically cover" all of the targets, allocating a random resource level to each of the targets. ${ }^{4}$

The results of our experiment support the theoretical prediction that, under the auction CSF, the attacker uses a "stochastic guerilla warfare strategy" (i.e., randomly attacking a single of target and ignoring the remaining targets) and the defender uses a "complete coverage

\footnotetext{
${ }^{3}$ Our focus on allowing both the defender and attacker to allocate endogenous levels of the resource to an endogenous number of targets contrasts with the reliability-theoretic approach to attack and defense which implicitly assumes that the attacker's allocation of the resource is fixed and is (almost everywhere) allocated to a single target. See for example Bier et al. (2007) and Powell (2007a, b).

${ }^{4}$ Moreover, for almost all configurations of the players' valuations of winning, one of the two players drops out with positive probability by allocating zero resources to each target, with the identity of the dropout determined by a measure of asymmetry in the conflict that takes into account both the ratio of the players' valuations, $\left(v_{A} / v_{D}\right)$, and the number of targets, $n$.
} 
strategy" (i.e., allocating a strictly positive level of resources to each target). The data show that the attacker launches at most one attack over $80 \%$ of the time and that the defender covers all of the targets around $90 \%$ of the time. In contrast, under the lottery CSF, the players' expenditures are distributed over the entire strategy space and are therefore inconsistent with the theoretical prediction of a pure-strategy Nash equilibrium. In fact, under the lottery CSF, the attacker utilizes a stochastic guerilla warfare strategy of attacking only a single target almost $45 \%$ of the time. Conversely, the attacker allocates a strictly positive level of resources to each and every target less than $30 \%$ of the time.

Finally, our results show that under both CSFs both players' resource expenditures exceed their respective theoretical predictions. Nonetheless, behavior appears to conform to the comparative statics of Nash equilibrium for the parameters chosen. For a given discrete increase in the attacker's valuation of a successful attack, $v_{A}$, the attacker's resource expenditure increases and the defender's expenditure decreases. As a result, the attacker's probability of winning also increases.

To date, there are only a few experimental studies that investigate games of multiple contests with linkages. Chowdhury et al. (2009) test several basic predictions of the original Colonel Blotto game as in Borel (1921) and find support for all major theoretical predictions. Avrahami and Kareev (2009) and Arad and Rubinstein (2009) investigate a discrete constantsum Blotto game as in Hart (2008). The current study extends the experimental literature on multidimensional contests or "Blotto-type" games by examining behavior in the "game of attack and defense" of a weakest-link network of targets under alternative specifications of the contest success function. 


\section{The Game of Attack and Defense}

Consider the following multiple contest game of attack and defense between two risk neutral players. The attacker $A$ and the defender $D$ simultaneously allocate their respective resources across the $n$ targets. The probability that each player wins target $i$ depends on the players' allocations of a one-dimensional resource to the target, $x_{A}^{i}$ and $x_{D}^{i}$, for $A$ and $D$ respectively. The players' resource expenditures are mapped into their respective probabilities of winning by the contest success function (CSF). One prominent contest success function is the Tullock CSF (Tullock, 1980). According to this CSF, players $A$ and $D$ win the target $i$ with probabilities:

$$
p_{A}^{i}\left(x_{A}^{i}, x_{D}^{i}\right)=\frac{\left(x_{A}^{i}\right)^{r}}{\left(x_{A}^{i}\right)^{r}+\left(x_{D}^{i}\right)^{r}} \quad \text { and } \quad p_{D}^{i}\left(x_{A}^{i}, x_{D}^{i}\right)=\frac{\left(x_{D}^{i}\right)^{r}}{\left(x_{A}^{i}\right)^{r}+\left(x_{D}^{i}\right)^{r}}
$$

for $\left(x_{A}^{i}, x_{D}^{i}\right) \neq(0,0)$ and $p_{A}^{i}\left(x_{A}^{i}, x_{D}^{i}\right)=p_{D}^{i}\left(x_{A}^{i}, x_{D}^{i}\right)=1 / 2$ otherwise. If $r=1$ (the lottery CSF), then each player's probability of winning the target equals the ratio of that player's resource expenditure to the sum of both of the players' resource expenditures. If $r=\infty$ (the auction CSF), then the player that allocates the higher level of resources wins the target with certainty. ${ }^{5}$

The attacker and the defender have asymmetric objectives. ${ }^{6}$ The defender's objective is to successfully defend all $n$ targets in the network, in which case he receives a "prize" of value $v_{D}$. Therefore, the expected payoff of $D$ is equal to his probability of winning all targets times the value of winning, minus the sum of all his resource expenditures across all of the targets:

$$
E\left(\pi_{D}\right)=\left(\prod_{i=1}^{n} p_{D}^{i}\left(x_{A}^{i}, x_{D}^{i}\right)\right) v_{D}-\sum_{i=1}^{n} x_{D}^{i}
$$

\footnotetext{
${ }^{5}$ In the case that the players allocate the same level of the resource to a target, it is assumed that the defender wins the target. However, a range of tie-breaking rules yields similar results. A detailed description of the theoretical model can be found in Clark and Konrad (2007) for the lottery CSF and Kovenock and Roberson (2010a) for the auction CSF.

${ }^{6}$ See also Milgrom (2007) who considers an example of a package auction in which the objective of some bidders may be to obtain all the goods (best-shot objective), if goods are perfect complements, while for other bidders the objective is to obtain only one good (weakest-link objective), if goods are perfect substitutes.
} 
The attacker's objective is to successfully attack at least one target, in which case he receives a "prize" of value $v_{A}$. The expected payoff of $A$ is equal to his probability of winning at least one target (which is 1 minus the probability that $D$ wins all targets) times the value of winning, minus the sum of all his resource expenditures:

$$
E\left(\pi_{A}\right)=\left(1-\prod_{i=1}^{n} p_{D}^{i}\left(x_{A}^{i}, x_{D}^{i}\right)\right) v_{A}-\sum_{i=1}^{n} x_{A}^{i}
$$

The nature of equilibrium in this game of attack and defense depends on the parameter $r$. Clark and Konrad (2007) characterize a Nash equilibrium for the lottery CSF $(r=1)$. We summarize their findings in the following proposition:

\section{Proposition 1. (Clark and Konrad, 2007)}

(i) If $v_{D} \geq(n-1) v_{A}$, then a pure-strategy Nash equilibrium exists in which player $A$ allocates $x_{A}^{*}=\frac{v_{A}^{2} v_{D}^{n}}{\left(v_{A}+v_{D}\right)^{n+1}}$ to every target and player $D$ allocates $x_{D}^{*}=\frac{v_{A} v_{D}^{n+1}}{\left(v_{A}+v_{D}\right)^{n+1}}$ to every target.

(ii) If $v_{D}<(n-1) v_{A}$, then a Nash equilibrium exists in which player $A$ allocates $x_{A}^{*}=$ $\frac{(n-1)^{n-1}}{n^{n+1}} v_{D}$ to each target and player $D$ randomizes by allocating $x_{D}^{*}=\frac{(n-1)^{n}}{n^{n+1}}$ to every target with probability $q^{*}=\frac{v_{D}}{(n-1) v_{A}}$ and $x_{D}^{*}=0$ to every target with the probability $1-q^{*}$

Proposition 1 is summarized as follows. If the ratio of the defender's valuation to the attacker's valuation exceeds a threshold, $v_{D} \geq(n-1) v_{A}$, then it is worthwhile for the defender to play a pure strategy that allocates the same level of resources to each target and defend all of the targets with probability one. However, if $v_{D}<(n-1) v_{A}$, the defender earns a zero expected payoff in equilibrium and the probability that the defender engages in the conflict by allocating the same positive level of resources to each target is only $q^{*}=\frac{v_{D}}{(n-1) v_{A}}$. For this range of values, 
the defender "surrenders" with strictly positive probability, allocating a zero level of the resource to every target. In contrast, for all parameter configurations the attacker plays a pure strategy. Although the attacker's objective is to win at least one target, due to the decreasing returns to expenditure exhibited by the lottery CSF, the optimal strategy is actually to attack each and every target with an identical strictly positive level of resources.

Kovenock and Roberson (2010a) characterize properties of the set of Nash equilibria for the game of attack and defense over a weakest-link network for the case of the auction CSF $(r=\infty)$. They show that all equilibria are in mixed strategies, where in this case a mixed strategy is an $n$-variate joint distribution function. That paper completely characterizes the set of equilibrium payoffs and univariate marginal distributions, which are unique for all parameter configurations. These results are summarized as follows:

\section{Proposition 2. (Kovenock and Roberson, 2010a)}

(i) If $v_{D} \geq n v_{A}$, then with probability $1-\frac{n v_{A}}{v_{D}}$ player $A$ allocates 0 to every target. With the remaining probability, $\frac{n v_{A}}{v_{D}}$, player $A$ randomly attacks a single target with a resource allocation drawn from a uniform distribution over the interval $\left[0, v_{A}\right]$. To each and every target, player $D$ allocates a random level of the resource drawn from a uniform distribution over the interval $\left[0, v_{A}\right]$. The players' sets of equilibrium univariate marginal distribution functions are unique, and for each target $j$ are given by: $F_{A}^{j}\left(x_{A}^{j}\right)=1-\frac{v_{A}}{v_{D}}+$ $\frac{x_{A}^{j}}{v_{D}}$ and $F_{D}^{j}\left(x_{D}^{j}\right)=\frac{x_{D}^{j}}{v_{A}}$, respectively, over the interval $\left[0, v_{A}\right]$

(ii) If $v_{D}<n v_{A}$, player $A$ randomly attacks a single target with a resource allocation drawn from a uniform distribution over the interval $\left[0, \frac{v_{D}}{n}\right]$. With probability $1-\frac{v_{D}}{n v_{A}}$ player $D$ allocates 0 to every target. With the remaining probability, $\frac{v_{D}}{n v_{A}}$, player $D$ allocates to each 
target a random level of resources drawn from a uniform distribution over the interval $\left[0, \frac{v_{D}}{n}\right]$. The players' sets of equilibrium univariate marginal distribution functions for every target are unique, and for each target $j$ are given by: $F_{A}^{j}\left(x_{A}^{j}\right)=1-\frac{1}{n}+\frac{x_{A}^{j}}{v_{D}}$ and $F_{D}^{j}\left(x_{D}^{j}\right)=1-\frac{v_{D}}{n v_{A}}+\frac{x_{D}^{j}}{v_{A}}$, respectively, over the interval $\left[0, \frac{v_{D}}{n}\right]$.

It is important to note that, although there are multiple equilibria in this game, there exists a unique set of equilibrium univariate marginal distribution functions. Kovenock and Roberson (2010a) also show that the equilibrium joint distribution functions exhibit several distinctive properties. For example, in all equilibria of the auction CSF game, the attacker optimally allocates a strictly positive amount of resources to at most one target (each target being chosen with positive probability) while the defender optimally allocates a strictly positive amount of resources to either all targets or no target. This particular property provides a striking contrast with the equilibrium in the lottery CSF game (see Proposition 1) in which the attacker allocates a strictly positive amount of resources to every target.

\section{Experimental Design and Procedures}

\subsection{Experimental Design}

Table 1 summarizes the experimental parameters. We employ a two-by-two design with four treatments, by varying the rules that determine the winner of a target (Lottery and Auction treatments), and by varying the values that determine whether the attacker or the defender 
receives a higher expected payoff (A and D treatments). In all four treatments there are four targets and two players (attacker and defender). ${ }^{7}$

The Lottery-D and Lottery-A treatments use the lottery CSF in which the probability that a player wins a given target is equal to the ratio of that player's allocation of resources to the target (tokens) to the sum of both players' allocations to that target. The payoff to the defender for successfully defending all targets is $v_{D}=200$ experimental francs. The payoff to the attacker for successfully attacking at least one target is $v_{A}=40$ francs in the Lottery-D treatment and $v_{A}=80$ francs in the Lottery-A treatment. ${ }^{8}$ For the parameter configuration in the Lottery-D treatment, Proposition 1 part (i) applies and in the pure-strategy equilibrium the attacker allocates 3.2 tokens to each target and the defender allocates 16.1 tokens to each target. For the parameter configuration in the Lottery-A treatment, Proposition 1 part (ii) applies and in equilibrium the attacker allocates 5.3 tokens to each target and the defender allocates 15.8 tokens to every target with probability 0.83 and 0 tokens to every target with probability 0.17 . In the Lottery-D treatment the defender has a sufficiently high valuation of a successful defense, relative to the attacker's valuation of a successful attack, that in equilibrium the defender ("D" stands for the defender) receives a significantly higher expected payoff than the attacker (32.2 versus 7.8). Conversely, in the Lottery-A treatment, it is the attacker ("A" stands for the attacker) who receives the higher payoff (37.8 versus 0 for the defender).

The only difference between the Auction-D (Auction-A) treatment and the Lottery-D (Lottery-A) treatment is that the winner of each target is determined by the auction CSF rather

\footnotetext{
${ }^{7}$ The experimental instructions used a context neutral language. For example, the attacker and the defender were called participant 1 and participant 2, while the targets were called boxes.

${ }^{8}$ We chose 4 targets and valuation ratios of 200/40 for Lottery-D and Auction-D treatments to ensure that the theoretical predictions are derived from Proposition 1 (i) and Proposition 2 (i). Similarly, we chose 4 targets and valuation ratios of 200/80 for Lottery-A and Auction-A treatments to match Proposition 1 (ii) and Proposition 2 (ii). The 4 targets and the ratio of the attacker's valuation to the defender's valuation were also chosen to ensure that the allocation problem for the subjects is non-trivial and so that both the attacker and the defender had substantial chances of winning some targets.
} 
than the lottery CSF. That is, in the auction treatments, the player who allocates the higher level of resources to a target wins that target with certainty. In both auction treatments, there are no pure-strategy equilibria. In the Auction-D treatment, in any mixed-strategy equilibrium the attacker attacks no targets with probability 0.2 and, with probability 0.8 , chooses exactly one target to attack at random and stochastically allocates between 0 and 40 tokens according to a uniform distribution. The defender randomizes according to a joint distribution function that, in addition to satisfying the necessary properties for equilibrium given by Kovenock and Roberson (2010a), stochastically allocates between 0 and 40 tokens to each target according to a uniform marginal distribution. In the Auction-A treatment, Proposition 2 part (ii) applies. In equilibrium the attacker randomly chooses one of the targets to attack and stochastically allocates between 0 and 50 tokens to that target according to a uniform distribution. The defender employs a strategy in which, with probability 0.375 he engages in no defensive efforts and, with probability 0.625 , the defender allocates a stochastic number of tokens, uniformly distributed between 0 and 50 , to each target. Because in the Auction-D treatment, the defender's valuation is sufficiently higher than the attacker's valuation, the defender has an expected payoff of 40 and the attacker has an expected payoff of 0 . In the Auction-A treatment, these roles are reversed and the attacker has a positive expected payoff equal to 40 and the defender has an expected payoff of 0 .

Our experiment tests six hypotheses motivated by the theoretical predictions. The first two hypotheses address the comparative static properties of equilibrium. ${ }^{9}$ The next two describe predictions concerning individual behavior of the attacker and defender in the lottery treatments. The final two hypotheses describe predictions concerning individual behavior of the attacker and defender in the auction treatments.

\footnotetext{
${ }^{9}$ Although the comparative statics results are framed in terms of a change in the attacker's valuation, due to invariance of preferences with respect to affine transformations of utility, the theoretical benchmark would also apply to a decrease in the unit cost of resource expenditure of the attacker.
} 
Hypothesis 1: In both the lottery and auction treatments, as the value of the attacker increases from 40 to 80 , the attacker's average resource allocation increases, the defender's average resource allocation decreases, and the attacker's probability of winning increases.

Hypothesis 2: In both the lottery and auction treatments, as the value of the attacker increases from 40 to 80 , the attacker's expected payoff increases and the defender's expected payoff decreases.

Hypothesis 3: In both the Lottery-D and Lottery-A treatments the attacker allocates a strictly positive and identical level of the resource across all targets.

Hypothesis 4: The defender always allocates a strictly positive and identical level of the resource across all targets in the Lottery-D treatment and does so with positive probability in the Lottery-A treatment. In the Lottery-A treatment the defender also allocates a zero level of the resource with positive probability.

Hypothesis 5: In both the Auction-D and Auction-A treatments the attacker plays a guerilla warfare strategy that allocates a random level of the resource to at most one target.

Hypothesis 6: In both the Auction-D and Auction-A treatments the defender allocates random levels of the resource across the targets. In the Auction-D treatment these random allocations are positive with probability one. In the Auction-A treatment the defender also allocates a zero level of the resource with positive probability.

\subsection{Experimental Procedures}

The experiment was conducted at the Vernon Smith Experimental Economics Laboratory. The computerized experimental sessions were run using z-Tree (Fischbacher, 2007). A total of 96 subjects participated in eight sessions, summarized in Table 2. All subjects were 
Purdue University undergraduate students who participated in only one session of this study.

Some students had participated in other economics experiments that were unrelated to this research.

Each experimental session had 12 subjects and proceeded in two parts, corresponding to the lottery and auction treatments. ${ }^{10}$ Each subject played for 20 periods in the Lottery-D (Auction-D) treatment and 20 periods in the Lottery-A (Auction-A) treatment. The sequence was varied so that half the sessions had the Lottery-A (Auction-A) treatment first, and half had the Lottery-D (Auction-D) treatment first.

In the first period of each treatment subjects were randomly and anonymously assigned as attacker or defender (participant 1 or participant 2). All subjects remained in the same role assignment for the first 10 periods and then changed their assignment for the last 10 periods. $^{11}$ Subjects of opposite assignments were randomly re-paired each period to form a new two-player group. Each period, subjects were asked to choose how many tokens to allocate to 4 targets (boxes). All subjects could allocate to each target any number of tokens between 0 and their valuation. The total number of tokens could not exceed the subject's valuation. All subjects were informed that regardless of who wins, they would have to forfeit all tokens allocated to each target. After all subjects made their allocations, the computer displayed the following information: allocations of the attacker, allocations of the defender, which targets they won, and individual earnings for the period. In the Lottery-A and Lottery-D treatments, the winner was

\footnotetext{
${ }^{10}$ Before the start of the experiment we also elicited subjects' risk preferences by utilizing a series of 15 lottery choices as in Holt and Laury (2002). Subjects were asked to state whether they preferred safe option A or risky option B. Option A yielded $\$ 1$ payoff with certainty, while option B yielded a payoff of either $\$ 3$ or $\$ 0$. The probability of receiving $\$ 3$ or $\$ 0$ varied across all 15 lotteries. The first lottery offered a $0 \%$ chance of winning $\$ 3$ and a $100 \%$ chance of winning $\$ 0$, while the last lottery offered a $70 \%$ chance of winning $\$ 3$ and a $30 \%$ chance of winning $\$ 0$.

${ }^{11}$ The main reason for using role switching is to avoid any social preferences, i.e. subjects who were assigned as disadvantaged attackers knew that they would also play the role of the advantaged defenders. The role switching also induces better learning, since subjects have an opportunity to learn strategies in the game in both roles.
} 
chosen according to the simple lottery rule, independently across targets. In the Auction-A and Auction-D treatments, the player who allocated more tokens to a particular target was chosen as the winner of that target. ${ }^{12}$

After completing all 40 decision periods (two treatments), 4 periods were randomly selected for payment ( 2 periods for each treatment). The sum of the total earnings for these 4 periods was exchanged at the rate of 26 tokens $=\$ 1$. Additionally, all players received a participation fee of $\$ 20$ to cover potential losses. On average, subjects earned $\$ 25$ each and this was paid in cash. Each experimental session lasted about 80 minutes.

\section{Results}

\subsection{General Results}

Table 3 summarizes the average allocation of tokens, the average payoff, and the probability of winning by the attacker and the defender in each treatment. The data support predictions formalized in Hypothesis 1 and Hypothesis 2. Consistent with Hypothesis 1, when the attacker's valuation increases from 40 to 80 , the average level of the resource allocated by the attacker increases from 4.4 to 7.8 under the lottery CSF, and it increases from 4.4 to 7.7 under the auction CSF. The average level of the resource allocated by the defender decreases from 24.4 to 15.8 under the auction CSF; however, it does not decrease under the lottery CSF (19.4 versus 19.3). ${ }^{13}$ Also, consistent with Hypothesis 1 , the attacker's probability of winning in Lottery-A

\footnotetext{
${ }^{12}$ When both players allocated the same amount to a given target, the computer always chose the defender as the winner of that target.

${ }^{13}$ To support these conclusions we estimated simple panel regressions, where the dependent variable is allocation to a target and the independent variables are a constant, a period trend, and treatment dummy-variables. The models included a random effects error structure, with the individual subject as the random effect, to account for the multiple efforts made by individual subjects. The standard errors were clustered at the session level to account for
} 
(0.68) is higher than his probability of winning in Lottery-D (0.51), and the probability of winning in Auction-A (0.68) is higher than the probability of winning in Auction-D (0.33). ${ }^{14}$ These findings support the conjecture that the attacker's advantage over the defender increases as the attacker's valuation increases.

The data also indicate that, as the attacker's valuation increases from 40 to 80 , the attacker's payoff increases and the defender's payoff decreases, supporting Hypothesis 2. From Table 3 it is clear that the defender's (attacker's) payoffs in the Lottery-D and Auction-D treatments are substantially higher (lower) than those in Lottery-A and Auction-A. Although the qualitative predictions of the theory are supported by our experiment, both player types receive significantly lower payoffs than predicted (Table 3). This is mainly because of the significant over-expenditure of resources in all treatments. In the Lottery-D treatment, the attacker allocates on average 4.4 tokens, instead of the predicted 3.2, and in the Lottery-A treatment, the attacker allocates 7.8 tokens, instead of 5.3. This translates into an average over-expenditure of $40 \%$. The relative magnitude of over-expenditure by the defender is similar: 19.4 tokens instead of 16.1 and 19.3 tokens instead of $13.1{ }^{15}$ Similar, patterns of over-expenditure can be observed in the Auction-A and Auction-D treatments. However, the magnitude of the over-expenditure is around $10 \%-20 \%{ }^{16}$ Significant over-expenditure in our experiment is consistent with previous experimental findings on all-pay auctions and lottery contests (Davis and Reilly, 1998; Potters et al., 1998; Gneezy and Smorodinsky, 2006; Sheremeta, 2010a, 2010b). Previous explanations suggest that subjects make mistakes (Potters et al., 1998; Goeree et al., 2002; Sheremeta, 2010a)

session effects. The treatment dummy-variables are significant in all regressions (p-values $<0.01$ ), except the one where we compare the behavior of the defender in the Lottery-A and Lottery-D treatments.

${ }^{14}$ These differences are significant (all p-values $<0.01$ ) based on the estimation of random effects probit models, where the dependent variable is whether the player won or not, and the independent variables are a constant, a period trend, and treatment dummy-variables.

${ }^{15}$ A standard Wald test, conducted on estimates of panel regression models, rejects the hypothesis that the average expenditures under lottery CSF are equal to the predicted theoretical values in Table 3 (all p-values $<0.05$ ).

16 The over-expenditures are significant only for the defender in the Auction-D treatment ( $\mathrm{p}$-value $<0.05$ ). 
or that they have a non-monetary value of winning (Goeree et al., 2002; Sheremeta, 2010b). The same arguments can be made to explain over-expenditure in our experiment.

\subsection{Individual Behavior in the Lottery Treatments}

Next we look at individual behavior of the attacker and defender in the lottery treatments. Theory predicts that under the lottery CSF, the attackers and defenders should allocate a uniform level of the resource across all targets. Nevertheless, contrary to Hypothesis 3 and Hypothesis 4, subjects' expenditures are distributed over the entire strategy space. Figure 1 displays, by player type and treatment, the cumulative distribution functions of the resource allocations. Note that in the Lottery-D and Lottery-A treatments there is significant variation in expenditures. Instead of placing a mass point at 3.2 in the Lottery-D treatment and 5.3 in the Lottery-A treatment, the attacker's resources are distributed between 0 and 50. The same is true for the defender. High variance in individual expenditures is consistent with previous experimental findings in the lottery contest literature (Davis and Reilly, 1998; Potters et al., 1998; Sheremeta, 2010a, 2010b). Several explanations have been offered. The first explanation for fluctuations in expenditure is based on the probabilistic nature of lottery contests, which may affect individual decisions from period to period (Chowdhury et al., 2009). A second explanation is that subjects have unobserved demographic differences that affect their individual behavior. Finally, it might be the case that subjects have different preferences towards risk that affect their behavior. Although the theoretical models of Clark and Konrad (2007) and Kovenock and Roberson (2010a) do not provide a prediction of the effect of risk preferences on players' expenditures, in our experiment we elicited a measure of risk attitudes from a series of lotteries (for the details see the appendix and footnote 10). The data provide some evidence that attitude towards risk is a good predictor 
of individual behavior in the game of attack and defense: less risk-averse subjects (in both the roles of attacker and defender) expend more resources than more risk-averse subjects. ${ }^{17}$ This may partially explain the distribution of the expenditures in the Lottery-D and Lottery-A treatments.

Another inconsistency with theoretical predictions stated in Hypothesis 3 is that, instead of attacking all of the targets in the Lottery-D and Lottery-A treatments, the attacker uses a "guerilla warfare" strategy that places a significant mass point at 0 . The magnitude of the mass point at 0 suggests that on average the attacker allocates a positive amount of resources to two targets and ignores the remaining two targets. Moreover, the individual data indicate that the attacker covers all of the targets only $28 \%$ of the time and, instead, almost $45 \%$ of the time the attacker leaves three targets intact. This interesting finding provides evidence that the auction CSF's theoretical prediction that the attacker uses a stochastic guerilla warfare strategy is observed under both the lottery and auction CSFs. One seemingly plausible explanation is that the attackers optimally adjust their strategy given the suboptimal behavior of the defenders. However, as we discuss in more detail in Section 4.4, this cannot be the case, because attacking all four targets is the most profitable strategy that the attacker can employ in the lottery treatments. It is also possible that the attackers use noisy best-responses (McKelvey and Palfrey, 1995). By making "errors," attackers may deviate from the optimal equal allocation of resources across all targets. However, it is important to emphasize that an allocation of zero to one of the targets is a fairly costly deviation for the attacker because for $x_{D}^{i}>0$ the derivative of $p_{A}^{i}\left(x_{A}^{i}, x_{D}^{i}\right)$ is infinite at $x_{A}^{i}=0$. Therefore, even if the attackers use noisy best-responses, it can only explain the high expenditure variance in the Lottery-A and Lottery-D treatments and not the

\footnotetext{
${ }^{17}$ We estimate several random effects models where the dependent variable is the allocation of tokens to all 4 targets and the independent variables are the dummies for risk-aversion, session, and treatment, and an inverse of a period trend. All specifications indicate that less risk-averse subjects (subjects who chose at least 10 safe options A in the lottery task) expend more resources than more risk-averse subjects. This difference is significant for the defenders but not for the attackers. The results of the estimation are available from the authors upon request.
} 
fact that attackers leave three targets intact $45 \%$ of time. Finally, it is possible that the attackers anchor their behavior to the fact that they need to successfully attack only one target in order to win, and therefore they ignore the strategic aspect of the game (Schelling, 1960). ${ }^{18}$

Although the behavior of the attacker is inconsistent with the theoretical predictions stated in Hypothesis 3, there is some evidence concerning the behavior of the defender that supports Hypothesis 4. In particular, theory predicts that in the Lottery-D treatment the defender always allocates a strictly positive and identical level of the resource to each target. The data indicate that the defender covers all targets in the Lottery-D treatment $93 \%$ of the time, supporting Hypothesis 4. However, contrary to Hypothesis 4, instead of allocating 16.1 to each target the defender's resources are distributed between 0 and 50 (see Figure 1). In the Lottery-A treatment, theory predicts that the defender covers all of the targets with probability 0.83 and none of the targets with probability 0.17 . Consistent with this prediction, the data indicate that the defender covers all of the targets $84 \%$ of the time and none of the targets $12 \%$ of the time. However, contrary to the theoretical prediction of a uniform allocation across targets, the defender's resources are distributed between 0 and 50 (see Figure 1).

\subsection{Individual Behavior in the Auction Treatments}

Next we look at individual behavior of the attacker and defender in the auction treatments. Theory predicts that under the auction CSF, the attacker should employ a "guerilla warfare" strategy that stochastically allocates zero resources to all but one target. Figure 2 displays the cumulative distribution functions of the resource allocations and it indicates that, in

\footnotetext{
${ }^{18}$ Such a heuristic strategy would also explain why individual behavior is so close to the theoretical predictions under the auction CSF (as we discuss later in this section).
} 
the aggregate, the attacker's behavior is consistent with this theoretical prediction. ${ }^{19}$ The "guerilla warfare" strategy is characterized by a significant mass point at 0 for the attacker in Figure 2. In the Auction-D and Auction-A treatments, the mass points at 0 for the attacker are 0.75 and 0.67 , respectively, which are close to the predicted values of 0.8 and $0.75 .{ }^{20}$ Moreover, the individual data also show substantial support for the theoretically optimal behavior of the attacker. For example, theory predicts that under the auction CSF the attacker should always leave three targets intact. The individual data show that this happens $89 \%$ of the time in the Auction-D treatment and $81 \%$ of the time in the Auction-A treatment. These findings provide substantial support for Hypothesis 5.

The behavior of the defender is also consistent with the theoretical predictions stated in Hypothesis 6. In particular, theory predicts that in the Auction-D treatment the defender uses a “complete coverage" strategy that allocates a strictly positive level of resources to each target with probability one. The data indicate that the defender covers all of the targets around $90 \%$ of the time. Moreover, consistent with the theoretical predictions, in the Auction-D treatment the defender's resources are uniformly distributed between 0 and 40 (see Figure 2). Similarly, in the Auction-A treatment the behavior of the defender is consistent with the theoretical predictions. Theory predicts that the defender should employ a strategy in which, with probability 0.375 he engages in no defensive efforts and, with probability 0.625 , the defender allocates a stochastic number of tokens, uniformly distributed between 0 and 50. The data indicate that the defender covers all four targets $62 \%$ of the time, three targets $2 \%$, two targets $2 \%$, one target $4 \%$, and zero

\footnotetext{
${ }^{19} \mathrm{We}$ combined the distribution of tokens to each of the 4 targets into one target, since marginal distributions to each target are identical across targets.

${ }^{20}$ In calculating the empirical mass points at 0 (Figures 1 and 2), we use an allocation of less than 1 token as an approximation of 0 . This approximation is used because the tie-breaking rule favors defenders, and therefore it may encourage attackers to place a very small allocation in some targets in order to reduce the tie-breaking disadvantage. However, even if we use only 0 allocations to compute mass points at 0 , we still get results that are close to the theoretical predictions (in Auction-D and Auction-A treatments, for example, the mass points at 0 for the attackers are 0.6 and 0.5 ).
} 
targets $30 \%$ of the time. ${ }^{21}$ Moreover, the defender's resources are uniformly distributed between 0 and 50 (see Figure 2). Overall, under the auction CSF, the behavior of the attacker and the defender is relatively close to the theoretical predictions, supporting Hypotheses 5 and 6.

\subsection{The Determinants of Payoffs}

Two interesting questions are: (i) whether suboptimal behavior by some subjects results in lower payoffs for those subjects and (ii) whether subjects can exploit the suboptimal behavior of their opponent by best responding to it. To answer this, we estimate random effects models of the following form:

$$
\begin{aligned}
\pi_{i t}=\text { const } & +\alpha\left(\sum_{h=1}^{4} x_{i t}^{h}\right)+\beta\left(\sum_{h=1}^{4} x_{i t}^{h}\right)^{2}+\sum_{h=1}^{4} A_{h} F_{A}^{h}+\sum_{h=1}^{4} D_{h} F_{D}^{h}+\gamma v_{A}+ \\
& +\delta(1 / t)+u_{i}+\varepsilon_{i t} .
\end{aligned}
$$

where $\pi_{i t}$ is player $i$ 's payoff in a period $t, \sum_{h=1}^{4} x_{i t}^{h}$ is the sum of tokens allocated to all four targets, $v_{A}$ is the attacker's valuation, and $1 / t$ is an inverse of a period trend. The dummy variables $F_{A}^{h}$ and $F_{D}^{h}$ indicate whether the attacker and defender made positive allocations to $h$ targets. All regressions also include dummy-variables to capture session effects.

The estimation results are shown in Table 4. First, note that the coefficient $\gamma$, which captures treatment effects, is significant in all specifications. The positive value of $\gamma$ in specifications (1) and (3) indicates that, under the lottery and auction CSFs, the attacker's payoff increases in the attacker's valuation. Similarly, the negative value of $\gamma$ in specifications (2) and (3) indicates that the defender's payoff decreases in the attacker's valuation. This finding

\footnotetext{
${ }^{21}$ The fact that the defender allocates 0 resources to all four targets $30 \%$ of the time may be a simple consequence of a behavioral spillover. As we mentioned previously, all subjects changed their role assignment (either as a defender or as an attacker) after 10 periods of the experiment, which might have triggered the defender to behave as the attacker during periods 11-20. Nevertheless, when we analyze the data only for the first 10 periods, we find a similar behavioral pattern for the defenders.
} 
supports the theoretical predictions of Propositions 1 and 2: the attacker's advantage over the defender increases when the attacker's valuation increases.

Specification (1) indicates that the attacker receives a significantly higher payoff when he allocates a strictly positive level of resources to all 4 targets (coefficient $A_{4}$ ). On the other hand, if the defender covers all of the targets with strictly positive resource levels, then the attacker receives a significantly lower payoff (coefficient $D_{4}$ ). Similarly, specification (2) indicates that if the defender allocates a strictly positive level of resources to all 4 targets, then he receives a higher payoff (coefficient $D_{4}$ ) than a defender who allocates resources to less than 4 targets (coefficients $D_{1}$ and $D_{23}$ ). These findings provide additional support for the theoretical argument of Clark and Konrad (2007), that under the lottery CSF a payoff-maximizing attacker will allocate a positive level of resources to each of the targets. By doing so, the attacker increases his expected payoff. It is interesting, therefore, that in our experiment the attackers often do not utilize this strategy but use, instead, a stochastic guerilla warfare strategy that consists of randomly attacking a subset of the targets and ignoring the remaining targets.

The Nash equilibrium prediction for the game of attack and defense over a weakest-link network is fundamentally different under the auction CSF (Kovenock and Roberson, 2010a). In all equilibria, the attacker allocates a strictly positive level of resources to at most one target, while the defender allocates resources to all of the targets in Auction-D and does so with a high positive probability in Auction-A. Specifications (3) and (4) indicate that when the defender allocates a strictly positive level of resources to all 4 targets, the defender significantly increases his payoff (coefficient $D_{4}$ in specification 4 ) and he significantly decreases the payoff of the attacker (coefficient $D_{4}$ in specification 3). On the other hand, an attack on only one target is 
associated with a reduction in payoff for the defender, relative to an attack on more than one target (in specification 4 coefficient $A_{1}$ is lower than $A_{23}$ and $A_{4}$ ).

\section{Conclusions}

This study experimentally investigates individual behavior in a game of attack and defense of a weakest-link network. The attacker's objective is to successfully attack at least one target and the defender's objective is to successfully defend all targets. We apply two benchmark contest success functions: the auction CSF and the lottery CSF. The results of our experiment indicate that under both CSFs both players' resource expenditures exceed their respective theoretical predictions. However, behavior appears to conform to the comparative statics of Nash equilibrium for the parameters chosen: as the attacker's valuation of success increases, the attacker's expenditure increases and the defender's expenditure decreases.

One of the most interesting findings is that the auction CSF's theoretical prediction that the attacker uses a "guerilla warfare" strategy and the defender uses a "complete coverage" strategy is observed under both the auction and lottery CSFs. This is inconsistent with Nash equilibrium behavior under the lottery CSF.

The current study contributes to the rapidly developing literature on defense against terrorism. ${ }^{22}$ The two recent studies by Clark and Konrad (2007) and Kovenock and Roberson (2010a) provide the first 'fully' strategic formal analyses of a simultaneous-move game of attack and defense that allows for an endogenous number of targets to be attacked and for endogenous

\footnotetext{
${ }^{22}$ Cadigan and Schmitt (2010) experimentally study terrorism and defense in the context of a two stage entry deterrence game, where in the first stage the government chooses defense expenditures and in the second stage terrorist groups decide whether to attack targets or not.
} 
choice of attack and defense effort. ${ }^{23}$ The striking difference between the predictions of the two models is that in equilibrium the attacker allocates resources to each and every target under the lottery CSF but only to at most one target under the auction CSF. Our experiment, however, provides evidence that under both the lottery and auction CSFs the attacker uses a stochastic guerilla warfare strategy, by randomly attacking a subset of the targets and ignoring the remaining targets. This interesting and sometimes suboptimal behavior by the attackers calls for further empirical research. The behavior of the attackers in our experiment also provides an alternative explanation for the empirical finding that "periods of high terrorism" seem to be relatively infrequent (Enders, 2007). The common explanation of such a phenomenon is that terrorists face a resource constraint, and therefore they cannot constantly attack all of the targets. Our experiment provides evidence that infrequent "periods of high terrorism" may simply be the result of asymmetric objectives and strategic interactions between the attackers and defenders within a weakest-link type of contest.

\footnotetext{
${ }^{23}$ Following Hausken (2008) there is also, within operations research, a line of literature that examines the attack and defense of series networks which are equivalent to the weakest-link networks examined here. Unfortunately, as Kovenock and Roberson (2010b) show, a technical error invalidates Hausken's characterization of Nash equilibrium for a substantial portion of the parameter space that he examines, and many of the existing results in that literature rely upon Hausken's (2008) characterization.
} 


\section{References}

Arad, A., \& Rubinstein, A. (2009). Colonel Blotto's Top Secret Files. Tel Aviv University, Working Paper.

Avrahami, J., \& Kareev, Y. (2009). Do the Weak Stand a Chance? Distribution of Resources in a Competitive Environment. Cognitive Science, 33, 940-950.

Bier, V.M., Oliveros, S., \& Samuelson, L. (2007). Choosing What to Protect: Strategic Defensive Allocation against an Unknown Attacker. Journal of Public Economic Theory, 9, 563-587.

Borel, E. (1921). La theorie du jeu les equations integrales a noyau symetrique. Comptes Rendus del Academie. 173, 1304-1308; English translation by Savage, L. (1953). The theory of play and integral equations with skew symmetric kernels. Econometrica, 21, 97-100.

Cadigan, J., \& Schmitt, P.M. (2010). Strategic Entry Deterrence and Terrorism: Theory and Experimental Evidence. Public Choice, 143, 3-22.

Chowdhury, S.M., Kovenock, D., \& Sheremeta, R.M. (2009). An Experimental Investigation of Colonel Blotto Games. Purdue University, Working Paper.

Clark, D.J., \& Konrad, K.A. (2007). Asymmetric Conflict: Weakest Link against Best Shot. Journal of Conflict Resolution, 51, 457-469.

Davis, D., \& Reilly, R. (1998). Do Many Cooks Always Spoil the Stew? An Experimental Analysis of Rent Seeking and the Role of a Strategic Buyer. Public Choice, 95, 89-115.

Enders, W. (2007). Terrorism: An Empirical Analysis. In K. Hartley and T. Sandler, (Eds.), Handbook of Defense Economics. Elvesier: Amsterdam, pp. 815 - 866.

Fischbacher, U. (2007). z-Tree: Zurich Toolbox for Ready-Made Economic Experiments. Experimental Economics, 10, 171-178.

Gneezy, U., \& Smorodinsky, R. (2006). All-Pay Auctions - An Experimental Study. Journal of Economic Behavior and Organization, 61, 255-275.

Goeree, J., Holt, C., Palfrey, T. (2002). Quantal Response Equilibrium and Overbidding in Private-Value Auctions. Journal of Economic Theory, 104, 247-272.

Hart, S. (2008). Discrete Colonel Blotto and General Lotto Games. International Journal of Game Theory, 36, 441-460.

Hausken, K. (2008). Strategic Defense and Attack for Series and Parallel Reliability Systems. European Journal of Operational Research, 186, 856-881.

Hirshleifer, J. (1983). From Weakest-Link to Best-Shot: the Voluntary Provision of Public Goods. Public Choice, 41, 371-386.

Holt, C.A. \& Laury, S.K. (2002). Risk Aversion and Incentive Effects. American Economic Review, 92, 1644-1655.

Kovenock, D., \& Roberson, B. (2010a). The Optimal Defense of Networks of Targets. Purdue University Working Paper No. 1251.

Kovenock, D., \& Roberson, B. (2010b). Strategic Defense and Attack for Series and Parallel Reliability Systems: Comment. Purdue University Working Paper No. 1253.

Kremer, M. (1993). The O-Ring Theory of Economic Development. Quarterly Journal of Economics, 108, 551- 575.

McKelvey, R., \& Palfrey, T. (1995). Quantal Response Equilibria for Normal Form Games. Games and Economic Behavior, 10, 6-38.

Milgrom, P. (2007). Package Auctions and Exchanges. Econometrica, 75, 935-965. 
Moore, T., Clayton, R., Anderson, R. (2009). The Economics of Online Crime. Journal of Economic Perspectives, 23, 3-20.

Potters, J.C., De Vries, C.G., \& Van Linden, F. (1998). An Experimental Examination of Rational Rent Seeking. European Journal of Political Economy, 14, 783-800.

Powell, R. (2007a). Defending Against Terrorist Attacks with Limited Resources. American Political Science Review, 101, 527-541.

Powell, R. (2007b). Allocating Defensive Resources with Private Information about Vulnerability. American Political Science Review, 101, 799-809.

Schelling, T. C. (1960). The Strategy of Conflict. Cambridge, Massachusetts: Harvard University Press.

Sheremeta, R.M. (2010a). Contest Design: An Experimental Investigation. Economic Inquiry, forthcoming.

Sheremeta, R.M. (2010b). Multi-Stage Elimination Contests: An Experimental Investigation. Games and Economic Behavior, 68, 731-747.

Tullock, G. (1980). Efficient Rent Seeking. In James M. Buchanan, Robert D. Tollison, Gordon Tullock, (Eds.), Toward a theory of the rent-seeking society. College Station, TX: Texas A\&M University Press, pp. 97-112.

US Congress (2002). Joint Inquiry into Intelligence Community Activities Before and After the Terrorist Attacks of September 11, 2001. Washington, DC: Senate Report No. 107-351, House Report No. 107-792. 


\section{Tables and Figures}

Table 1: Experimental Parameters and Theoretical Predictions

\begin{tabular}{cccccc}
\hline \hline Treatment & Player & Value & $\begin{array}{c}\text { Average } \\
\text { Allocation }\end{array}$ & $\begin{array}{c}\text { Expected } \\
\text { Payoff }\end{array}$ & $\begin{array}{c}\text { Probability } \\
\text { of Winning }\end{array}$ \\
\hline \multirow{2}{*}{ Lottery-D } & $A$ & 40 & 3.2 & 7.8 & 0.52 \\
& $D$ & 200 & 16.1 & 32.2 & 0.48 \\
\cline { 2 - 6 } Lottery-A & $A$ & 80 & 5.3 & 37.8 & 0.74 \\
& $D$ & 200 & 13.1 & 0.0 & 0.26 \\
\hline \multirow{2}{*}{ Auction-D } & $A$ & 40 & 4.0 & 0.0 & 0.40 \\
& $D$ & 200 & 20.0 & 40.0 & 0.60 \\
\cline { 2 - 6 } Auction-A & $A$ & 80 & 6.3 & 30.0 & 0.69 \\
& $D$ & 200 & 15.6 & 0.0 & 0.31 \\
\hline
\end{tabular}

Table 2: Experimental Sessions

\begin{tabular}{ccccc}
\hline $\begin{array}{c}\text { Session } \\
\text { Number }\end{array}$ & Design & $\begin{array}{c}\text { Matching } \\
\text { Protocol }\end{array}$ & $\begin{array}{c}\text { Participants } \\
\text { per Session }\end{array}$ & $\begin{array}{c}\text { Periods per } \\
\text { Treatment }\end{array}$ \\
\hline $1-2$ & Lottery-D $\rightarrow$ Lottery-A & Strangers & 12 & 20 \\
$3-4$ & Lottery-A $\rightarrow$ Lottery-D & Strangers & 12 & 20 \\
$5-6$ & Auction-D $\rightarrow$ Auction-A & Strangers & 12 & 20 \\
$7-8$ & Auction-A $\rightarrow$ Auction-D & Strangers & 12 & 20 \\
\hline
\end{tabular}

Table 3: Average Allocation, Payoffs, and Probability of Winning

\begin{tabular}{|c|c|c|c|c|c|c|c|c|}
\hline \multirow[t]{2}{*}{ Treatment } & \multirow[t]{2}{*}{ Player } & \multirow[t]{2}{*}{ Value } & \multicolumn{2}{|c|}{$\begin{array}{c}\text { Average } \\
\text { Allocation }\end{array}$} & \multicolumn{2}{|c|}{$\begin{array}{c}\text { Expected } \\
\text { Payoff }\end{array}$} & \multicolumn{2}{|c|}{$\begin{array}{l}\text { Probability } \\
\text { of Winning }\end{array}$} \\
\hline & & & Predicted & Actual & Predicted & Actual & Predicted & Actua \\
\hline \multirow{2}{*}{ Lottery-D } & $A$ & 40 & 3.2 & $4.4(0.1)$ & 7.8 & 2.7 & 0.52 & 0.51 \\
\hline & $D$ & 200 & 16.1 & $19.4(0.5)$ & 32.2 & 20.6 & 0.48 & 0.49 \\
\hline \multirow{2}{*}{ Lottery-A } & $A$ & 80 & 5.3 & $7.8(0.2)$ & 37.8 & 23.6 & 0.74 & 0.68 \\
\hline & $D$ & 200 & 13.1 & $19.3(0.6)$ & 0.0 & -14.1 & 0.26 & 0.32 \\
\hline \multirow{2}{*}{ Auction-D } & $A$ & 40 & 4.0 & $4.4(0.2)$ & 0.0 & -4.5 & 0.40 & 0.33 \\
\hline & $D$ & 200 & 20.0 & $24.4(0.6)$ & 40.0 & 36.2 & 0.60 & 0.67 \\
\hline \multirow{2}{*}{ Auction-A } & $A$ & 80 & 6.3 & $7.7(0.2)$ & 30.0 & 23.2 & 0.69 & 0.68 \\
\hline & $D$ & 200 & 15.6 & $15.8(0.7)$ & 0.0 & 3.9 & 0.31 & 0.32 \\
\hline
\end{tabular}

Standard error of the mean in parentheses. 
Table 4: Determinants of Payoff

\begin{tabular}{|c|c|c|c|c|}
\hline \multirow{2}{*}{ Dependent variable, payoff } & \multicolumn{2}{|c|}{ Lottery CSF } & \multicolumn{2}{|c|}{ Auction CSF } \\
\hline & Attacker & Defender & Attacker & Defender \\
\hline Specification & (1) & (2) & (3) & (4) \\
\hline$\alpha{ }_{\text {[sum of tokens allocation] }}$ & $\begin{array}{c}0.26 \\
(0.16)\end{array}$ & $\begin{array}{c}0.24 \\
(0.19)\end{array}$ & $\begin{array}{l}-0.17 \\
(0.13)\end{array}$ & $\begin{array}{l}-0.40 \\
(0.21)\end{array}$ \\
\hline$\beta$ [sum of tokens allocation squared] & $\begin{array}{c}-0.01 * * \\
(0.00)\end{array}$ & $\begin{array}{c}-0.00^{* *} \\
(0.00)\end{array}$ & $\begin{array}{c}0.00 \\
(0.00)\end{array}$ & $\begin{array}{c}0.00 \\
(0.00)\end{array}$ \\
\hline$A_{1}{ }_{\text {[attack } 1 \text { target] }}$ & $\begin{array}{c}6.21 \\
(3.69)\end{array}$ & $\begin{array}{c}-109.54 * \\
(10.33)\end{array}$ & $\begin{array}{c}2.33 \\
(2.58)\end{array}$ & $\begin{array}{c}-99.00 * * \\
(7.19)\end{array}$ \\
\hline $\begin{array}{l}A_{23} \\
\quad \text { [attack } 2 \text { or } 3 \text { targets] }\end{array}$ & $\begin{array}{c}5.09 \\
(4.16)\end{array}$ & $\begin{array}{c}-110.68^{* *} \\
(11.39)\end{array}$ & $\begin{array}{c}4.14 \\
(3.63)\end{array}$ & $\begin{array}{r}-71.16^{* *} \\
(10.11)\end{array}$ \\
\hline $\mathrm{A}_{4}$ & $\begin{array}{l}7.12 * \\
(3.44)\end{array}$ & $\begin{array}{c}-118.97 * * \\
(9.33)\end{array}$ & $\begin{array}{c}2.17 \\
(2.70)\end{array}$ & $\begin{array}{c}-71.01 * * \\
(8.00)\end{array}$ \\
\hline $\begin{array}{l}D_{1} \\
\quad \text { [defend } 1 \text { target] }\end{array}$ & $\begin{array}{l}-1.59 \\
(2.44)\end{array}$ & $\begin{array}{c}-26.05^{* *} \\
(7.49)\end{array}$ & $\begin{array}{c}-12.50^{*} \\
(4.19)\end{array}$ & $\begin{array}{l}-3.29 \\
(8.86)\end{array}$ \\
\hline $\begin{array}{l}D_{23} \\
\text { [defend } 2 \text { or } 3 \text { targets] }\end{array}$ & $\begin{array}{l}-2.71 \\
(3.35)\end{array}$ & $\begin{array}{c}-40.99 * * \\
(13.17)\end{array}$ & $\begin{array}{c}-25.71 * * \\
(4.37)\end{array}$ & $\begin{array}{l}-4.55 \\
(17.05)\end{array}$ \\
\hline$D_{4}$ & $\begin{array}{c}-28.88 * * \\
(2.18)\end{array}$ & $\begin{array}{c}1.29 \\
(8.34)\end{array}$ & $\begin{array}{c}-33.29 * * \\
(2.20)\end{array}$ & $\begin{array}{c}20.49 * * \\
(7.63)\end{array}$ \\
\hline$\gamma$ & $\begin{array}{c}0.59 * * \\
(0.06)\end{array}$ & $\begin{array}{c}-0.72^{* *} \\
(0.15)\end{array}$ & $\begin{array}{l}0.56^{* *} \\
(0.05)\end{array}$ & $\begin{array}{c}-0.77 * * \\
(0.15)\end{array}$ \\
\hline$\delta \quad$ [inverse of a period trend] & $\begin{array}{l}-9.43^{*} \\
(4.22)\end{array}$ & $\begin{array}{c}4.85 \\
(14.71)\end{array}$ & $\begin{array}{c}-10.64^{* *} \\
(4.02)\end{array}$ & $\begin{array}{l}-5.50 \\
(10.85)\end{array}$ \\
\hline Observations & 960 & 960 & 960 & 960 \\
\hline
\end{tabular}

* significant at 5\%, ** significant at $1 \%$.

Robust standard errors in parentheses. Random effect models account for individual characteristics of subjects. In each regression we control for session effects. 
Figure 1: CDF of Tokens in Lottery-D and Lottery-A Treatments
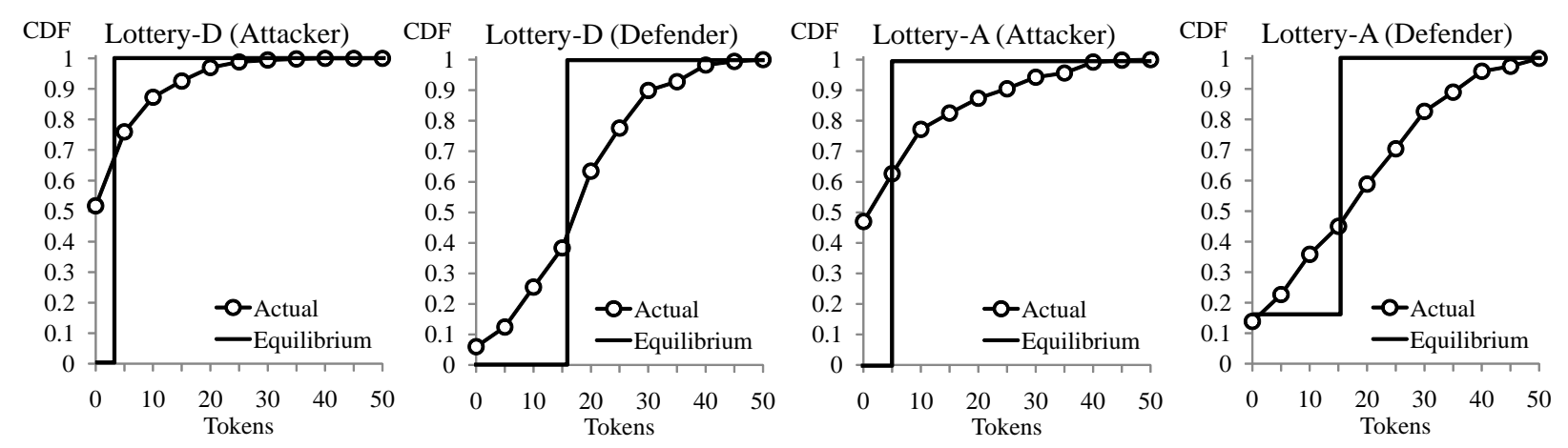

\section{Figure 2: CDF of Tokens in Auction-D and Auction-A Treatments}
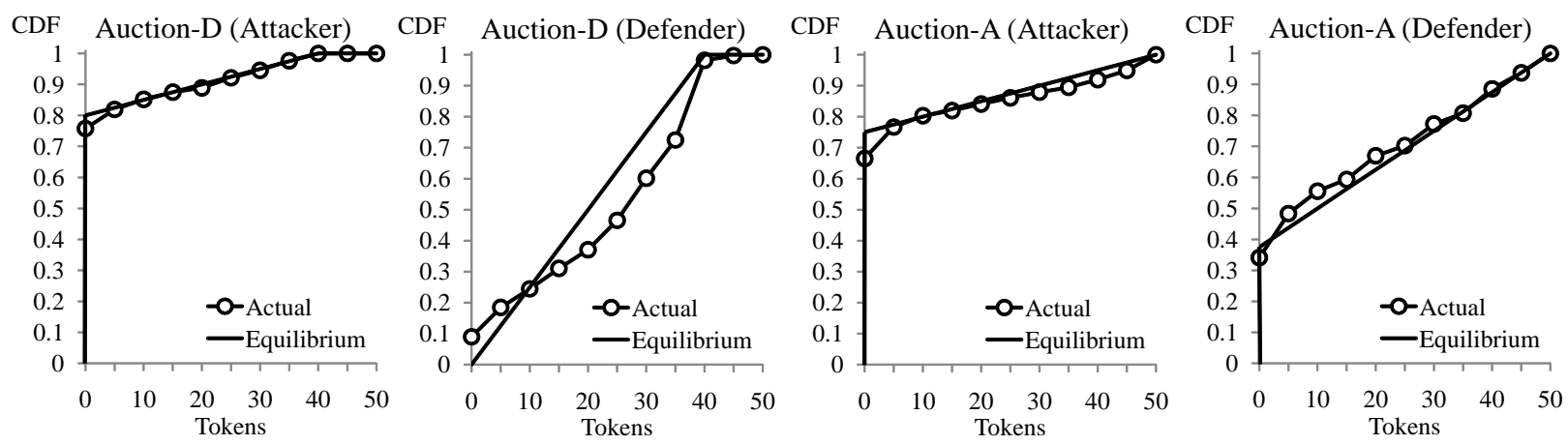


\section{Appendix (Lottery-D and Lottery-A)}

\section{GENERAL INSTRUCTIONS}

This is an experiment in the economics of strategic decision making. Various research agencies have provided funds for this research. The instructions are simple. If you follow them closely and make careful decisions, you can earn an appreciable amount of money.

The experiment will proceed in three parts. Each part contains decision problems that require you to make a series of economic choices which determine your total earnings. The currency used in Part 1 of the experiment is U.S. Dollars. The currency used in Parts 2 and 3 of the experiment is francs. Francs will be converted to U.S. Dollars at a rate of $\underline{\mathbf{2 6}}$ francs to $\_$d dollar. You have already received a $\mathbf{\$ 2 0 . 0 0}$ participation fee. At the end of today's experiment, you will be paid in private and in cash. 12 participants are in today's experiment.

It is very important that you remain silent and do not look at other people's work. If you have any questions, or need assistance of any kind, please raise your hand and an experimenter will come to you. If you talk, laugh, exclaim out loud, etc., you will be asked to leave and you will not be paid. We expect and appreciate your cooperation. At this time we proceed to Part 1 of the experiment.

\section{INSTRUCTIONS FOR PART 1}

In this part of the experiment you will be asked to make a series of choices in decision problems. How much you receive will depend partly on chance and partly on the choices you make. The decision problems are not designed to test you. What we want to know is what choices you would make in them. The only right answer is what you really would choose.

For each line in the table in the next page, please state whether you prefer option A or option B. Notice that there are a total of $\mathbf{1 5}$ lines in the table but just one line will be randomly selected for payment. Each line is equally likely to be chosen, so you should pay equal attention to the choice you make in every line. After you have completed all your choices a token will be randomly drawn out of a bingo cage containing tokens numbered from 1 to 15. The token number determines which line is going to be paid.

Your earnings for the selected line depend on which option you chose: If you chose option A in that line, you will receive $\mathbf{\$ 1}$. If you chose option B in that line, you will receive either $\mathbf{\$ 3}$ or $\mathbf{\$ 0}$. To determine your earnings in the case you chose option B there will be second random draw. A token will be randomly drawn out of the bingo cage now containing twenty tokens numbered from 1 to 20. The token number is then compared with the numbers in the line selected (see the table). If the token number shows up in the left column you earn $\$ 3$. If the token number shows up in the right column you earn $\$ 0$.

Are there any questions?

\begin{tabular}{|c|c|c|c|c|}
\hline $\begin{array}{l}\text { Decis } \\
\text { ion } \\
\text { no. }\end{array}$ & $\begin{array}{c}\text { Option } \\
\text { A }\end{array}$ & & $\begin{array}{c}\text { Option } \\
\text { B }\end{array}$ & $\begin{array}{l}\text { Please } \\
\text { choose } \\
\text { A or B }\end{array}$ \\
\hline 1 & $\$ 1$ & \$3 never & $\mathbf{\$ 0}$ if $1,2,3,4,5,6,7,8,9,10,11,12,13,14,15,16,17,18,19,20$ & \\
\hline 2 & $\$ 1$ & $\mathbf{\$ 3}$ if 1 comes out of the bingo cage & $\$ 0$ if $2,3,4,5,6,7,8,9,10,11,12,13,14,15,16,17,18,19,20$ & \\
\hline 3 & $\$ 1$ & $\$ 3$ if 1 or 2 & $\$ 0$ if $3,4,5,6,7,8,9,10,11,12,13,14,15,16,17,18,19,20$ & \\
\hline 4 & $\$ 1$ & $\mathbf{\$ 3}$ if $1,2,3$ & $\mathbf{\$ 0}$ if $4,5,6,7,8,9,10,11,12,13,14,15,16,17,18,19,20$ & \\
\hline 5 & $\$ 1$ & $\mathbf{\$ 3}$ if $1,2,3,4$ & $\$ 0$ if $5,6,7,8,9,10,11,12,13,14,15,16,17,18,19,20$ & \\
\hline 6 & $\$ 1$ & $\mathbf{\$ 3}$ if $1,2,3,4,5$ & $\mathbf{\$ 0}$ if $6,7,8,9,10,11,12,13,14,15,16,17,18,19,20$ & \\
\hline 7 & $\$ 1$ & $\$ \mathbf{3}$ if $1,2,3,4,5,6$ & $\$ 0$ if $7,8,9,10,11,12,13,14,15,16,17,18,19,20$ & \\
\hline 8 & $\$ 1$ & $\mathbf{\$ 3}$ if $1,2,3,4,5,6,7$ & $\mathbf{\$ 0}$ if $8,9,10,11,12,13,14,15,16,17,18,19,20$ & \\
\hline 9 & $\$ 1$ & $\mathbf{\$ 3}$ if $1,2,3,4,5,6,7,8$ & $\mathbf{\$ 0}$ if $9,10,11,12,13,14,15,16,17,18,19,20$ & \\
\hline 10 & $\$ 1$ & $\mathbf{\$ 3}$ if $1,2,3,4,5,6,7,8,9$ & $\$ 0$ if $10,11,12,13,14,15,16,17,18,19,20$ & \\
\hline 11 & $\$ 1$ & $\mathbf{\$ 3}$ if $1,2,3,4,5,6,7,8,9,10$ & $\$ 0$ if $11,12,13,14,15,16,17,18,19,20$ & \\
\hline 12 & $\$ 1$ & $\mathbf{\$ 3}$ if $1,2,3,4,5,6,7,8,9,10,11$ & $\mathbf{\$ 0}$ if $12,13,14,15,16,17,18,19,20$ & \\
\hline 13 & $\$ 1$ & $\mathbf{\$ 3}$ if $1,2,3,4,5,6,7,8,9,10,11,12$ & $\$ 0$ if $13,14,15,16,17,18,19,20$ & \\
\hline 14 & $\$ 1$ & $\mathbf{\$ 3}$ if $1,2,3,4,5,6,7,8,9,10,11,12,13$ & $\$ 0$ if $14,15,16,17,18,19,20$ & \\
\hline 15 & $\$ 1$ & $\mathbf{\$ 3}$ if $1,2,3,4,5,6,7,8,9,10,11,12,13,14$ & $\$ 0$ if $15,16,17,18,19,20$ & \\
\hline
\end{tabular}




\section{INSTRUCTIONS FOR PART 2}

The second part of the experiment consists of $\mathbf{2 0}$ decision-making periods. At the beginning of the first period, you will be randomly assigned either as participant $\mathbf{1}$ or as participant $\mathbf{2}$. You will stay in the same role assignment for the first 10 periods and then change your role assignment for the last 10 periods of the experiment. Each period you will be randomly re-paired with another participant of opposite assignment to form a two-person group. So, if you are participant 1, each period you will be randomly re-paired with another participant 2. If you are participant 2 , each period you will be randomly re-paired with another participant 1 .

Each period, both participants will choose how many tokens to allocate to 4 boxes in order to receive a reward. Each token costs $\mathbf{1}$ franc. The reward is worth $\mathbf{2 0 0}$ francs to participant 1 and $\mathbf{4 0}$ francs to participant 2 . An example of a decision screen is shown below.

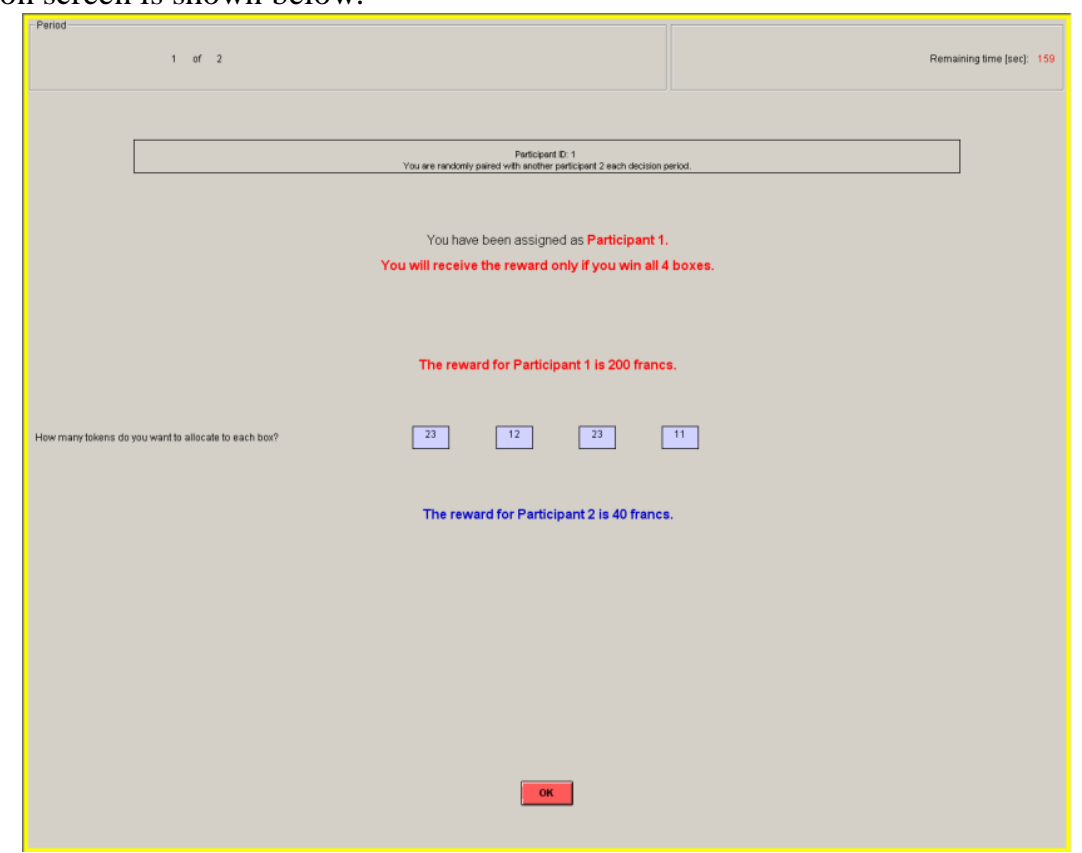

Participant 1 can allocate any number of tokens between $\mathbf{0}$ and $\mathbf{2 0 0}$ (including 0.1 decimal points) to each box. The total number of tokens in all boxes cannot exceed 200. Similarly, participant 2 can allocate any number of tokens between $\mathbf{0}$ and $\mathbf{4 0}$ (including 0.1 decimal points). The total number of tokens in all boxes cannot exceed $\mathbf{4 0}$.

The more tokens you allocate to a particular box, the more likely you are to win that box. The more tokens the other participant allocates to the same box, the less likely you are to win that box. Specifically, for each token you allocate to a particular box you will receive 10 lottery tickets. At the end of each period the computer draws randomly one ticket among all the tickets purchased by you and the other participant in your group. The owner of the drawn ticket wins. Thus, your chance of winning a particular box is given by the number of tokens you allocate to that box divided by the total number of tokens you and the other participant allocate to that box.

Chance of Number of tokens you allocate to that box

winning a box $=$ Number of tokens you allocate + Number of tokens the other participant allocates to that box In case both participants allocate zero to the same box, the computer will randomly chose a winner of that box. Therefore, each participant has the same chance of winning the box.

\section{Example of the Random Draw}

This is a hypothetical example used to illustrate how the computer makes a random draw. Let's say participant 1 and participant 2 allocate their tokens to the 4 boxes in the following way.

\begin{tabular}{|c|c|c|r|r|}
\hline Box & Participant 1 & Participant 2 & $\begin{array}{c}\text { Chance of winning the box } \\
\text { for Participant 1 }\end{array}$ & $\begin{array}{c}\text { Chance of winning the box } \\
\text { for Participant 2 }\end{array}$ \\
\hline 1 & 20.2 & 15 & $20.2 /(20.2+15)=0.57$ & $15 /(20.2+15)=0.43$ \\
2 & 18.5 & 15 & $18.5 /(18.5+15)=0.55$ & $15 /(18.5+15)=0.45$ \\
3 & 25 & 0 & $25 /(25+0)=1.00$ & $0 /(25+0)=0.00$ \\
4 & 40 & 5 & $40 /(40+5)=0.89$ & $5 /(40+5)=0.11$ \\
\hline Total & 103.7 & 35 & & \\
\hline
\end{tabular}

Participant 1 allocates 20.2 tokens to box 1, 18.5 tokens to box 2,25 tokens box 3 , and 40 tokens to box 4 (a total of 103.7 tokens). Participant 2 allocates 15 tokens to box 1, 15 tokens to box 2, 0 tokens to box 3, and 5 
tokens to box 4 (a total of 35 tokens). Therefore, the computer will assign lottery tickets to participant 1 and to participant 2 according to their allocation of tokens.

For example, in box 1, the computer will assign 202 lottery tickets to participant 1 and 150 lottery tickets to participant 2 . Then the computer will randomly draw one lottery ticket out of $352(202+150)$. As you can see, participant 1 has a higher chance of winning box 1: 20.2/(20.2+15) $=0.57$. Participant 2 has lower chance of winning box 1: $15 /(20.2+15)=0.43$.

Similarly, in box 3, the computer will assign 250 lottery tickets to participant 1 and 0 lottery tickets to participant 2. Then the computer will randomly draw one lottery ticket out of $250(250+0)$. As you can see, participant 2 has no chance of winning box 3: $0 /(25+0)=0.0$. Therefore, participant 1 will win box 3 for sure: $25 /(25+0)=1.0$.

\section{YOUR EARNINGS}

After both participants allocate their tokens and press the OK button, the computer will make a random draw for each box separately and independently. The random draws made by the computer will decide which boxes you win. Then the computer will assign a reward either to participant 1 or participant 2 . The computer will assign a reward to participant 1 only if participant 1 wins all 4 boxes. Otherwise, the computer will assign the reward to participant 2. The reward is worth $\mathbf{2 0 0}$ francs to participant 1 and $\mathbf{4 0}$ francs to participant 2. Regardless of who receives the reward, both participants will have to pay for the tokens they allocated to the 4 boxes (each token costs $1 \mathrm{franc})$. Thus, the period earnings will be calculated in the following way:

If participant 1 receives the reward:

Participant 1's earnings $=200$ - Tokens allocated to 4 boxes

Participant 2's earnings $=0$ - Tokens allocated to 4 boxes

If participant 2 receives the reward:

Participant 1 's earnings $=0$ - Tokens allocated to 4 boxes

Participant 2's earnings $=40$ - Tokens allocated to 4 boxes

Remember you have already received a $\$ \mathbf{2 0 . 0 0}$ participation fee (equivalent to 520 francs). Depending on the outcome in a given period, you may receive either positive or negative earnings. At the end of the experiment we will randomly select 1 out of the first 10 periods and 1 out of the last 10 periods of the experiment for actual payment. You will sum the total earnings for these two periods and convert them to a U.S. dollar payment. If the earnings are negative, we will subtract them from your participation fee. If the earnings are positive, we will add them to your participation fee.

At the end of each period, the allocation of your tokens, the allocation of the other participant's tokens, which boxes you win, whether you received the reward or not, and your period earnings are reported on the outcome screen as shown below. Once the outcome screen is displayed you should record your results for the period on your Personal Record Sheet under the appropriate heading.

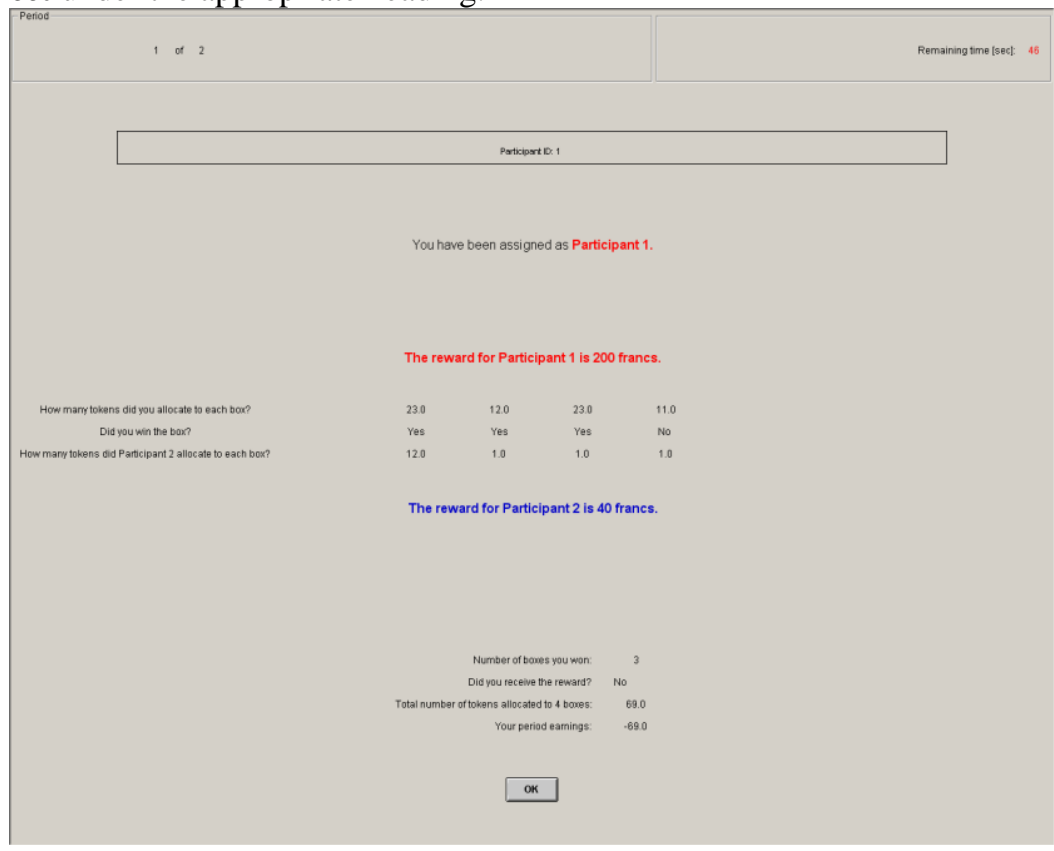




\section{IMPORTANT NOTES}

At the beginning of the first period, you will be randomly assigned either as participant 1 or as participant 2. You will stay in the same role assignment for the first 10 periods and then change your role assignment for the last 10 periods of the experiment. Each period you will be randomly re-paired with another participant of opposite assignment to form a two-person group. So, if you are participant 1, each period you will be randomly re-paired with another participant 2. If you are participant 2 , each period you will be randomly re-paired with another participant 1 .

Both participants will choose how many tokens to allocate to 4 boxes. After both participants allocate their tokens, the computer will make a random draw for each box separately and independently. You can never guarantee that you will win a particular box. However, by increasing your allocation to that box, you can increase your chance of winning that box. The computer will assign a reward to participant 1 only if participant 1 wins all 4 boxes. Otherwise, the computer will assign the reward to participant 2. Regardless of who receives the reward, both participants will have to pay for the tokens they allocated to 4 boxes. At the end of the experiment we will randomly select 1 out of the first 10 periods and 1 out of the last 10 periods of the experiment for actual payment. You will sum the total earnings for these two periods and convert them to a U.S. dollar payment.

Are there any questions?

\section{INSTRUCTIONS FOR PART 3}

The third part of the experiment consists of $\mathbf{2 0}$ decision-making periods. The rules for Part 3 are exactly the same as the rules for Part 2. As in Part 2, at the beginning of the first period, you will be randomly assigned either as participant 1 or as participant 2. You will stay in the same role assignment for the first 10 periods and then change your role assignment for the last 10 periods of the experiment. Each period you will be randomly repaired with another participant of opposite assignment to form a two-person group. So, if you are participant 1, each period you will be randomly re-paired with another participant 2 . If you are participant 2, each period you will be randomly re-paired with another participant 1 .

Each period, both participants will choose how many tokens to allocate to 4 boxes in order to receive a reward. Each token costs 1 franc. The only difference from Part 2 is that in Part 3 the reward is worth 200 francs to participant 1 and $\mathbf{8 0}$ francs (instead of 40 francs) to participant 2. Participant 1 can allocate any number of tokens between $\mathbf{0}$ and $\mathbf{2 0 0}$ (including 0.1 decimal points) to each box. The total number of tokens in all boxes cannot exceed 200. Similarly, participant 2 can allocate any number of tokens between $\mathbf{0}$ and $\mathbf{8 0}$ (including 0.1 decimal points). The total number of tokens in all boxes cannot exceed $\mathbf{8 0}$.

After both participants allocate their tokens and press the OK button, the computer will make a random draw for each box separately and independently. The random draws made by the computer will decide which boxes you win. Then the computer will assign a reward either to participant 1 or participant 2 . The computer will assign a reward to participant 1 only if participant 1 wins all 4 boxes. Otherwise, the computer will assign the reward to participant 2. The reward is worth $\mathbf{2 0 0}$ francs to participant 1 and $\mathbf{8 0}$ francs to participant 2. Regardless of who receives the reward, both participants will have to pay for the tokens they allocated to the 4 boxes (each token costs 1 franc).

At the end of each period, the allocation of your tokens, the allocation of the other participant's tokens, which boxes you win, whether you received the reward or not, and your period earnings are reported on the outcome screen. Once the outcome screen is displayed you should record your results for the period on your Personal Record Sheet under the appropriate heading. At the end of the experiment we will randomly select 1 out of the first 10 periods and 1 out of the last 10 periods of the experiment for actual payment. You will sum the total earnings for these two periods and convert them to a U.S. dollar payment.

Are there any questions? 


\section{Economic Science Institute Working Papers}

2010

10-11 Wilson, B., Jaworski, T., Schurter, K. and Smyth, A. An Experimental Economic History of Whalers' Rules of Capture.

10-10 DeScioli, P. and Wilson, B. Mine and Thine: The Territorial Foundations of Human Property.

10-09 Cason, T., Masters, W. and Sheremeta, R. Entry into Winner-Take-All and Proportional-Prize Contests: An Experimental Study.

10-08 Savikhin, A. and Sheremeta, R. Simultaneous Decision-Making in Competitive and Cooperative Environments.

10-07 Chowdhury, S. and Sheremeta, R. A generalized Tullock contest.

10-06 Chowdhury, S. and Sheremeta, R. The Equivalence of Contests.

10-05 Shields, T. Do Analysts Tell the Truth? Do Shareholders Listen? An Experimental Study of Analysts' Forecasts and Shareholder Reaction.

10-04 Lin, S. and Rassenti, S. Are Under- and Over-reaction the Same Matter? A Price Inertia based Account.

10-03 Lin, S. Gradual Information Diffusion and Asset Price Momentum.

10-02 Gjerstad, S. and Smith, V. Household expenditure cycles and economic cycles, 1920 - 2010.

10-01 Dickhaut, J., Lin, S., Porter, D. and Smith, V. Durability, Re-trading and Market Performance.

2009

09-11 Hazlett, T., Porter, D., Smith, V. Radio Spectrum and the Disruptive Clarity OF Ronald Coase.

09-10 Sheremeta, R. Expenditures and Information Disclosure in Two-Stage Political Contests.

09-09 Sheremeta, R. and Zhang, J. Can Groups Solve the Problem of Over-Bidding in Contests?

09-08 Sheremeta, R. and Zhang, J. Multi-Level Trust Game with "Insider" Communication.

09-07 Price, C. and Sheremeta, R. Endowment Effects in Contests.

09-06 Cason, T., Savikhin, A. and Sheremeta, R. Cooperation Spillovers in Coordination Games.

09-05 Sheremeta, R. Contest Design: An Experimental Investigation.

09-04 Sheremeta, R. Experimental Comparison of Multi-Stage and One-Stage Contests. 
09-03 Smith, A., Skarbek, D., and Wilson, B. Anarchy, Groups, and Conflict: An Experiment on the Emergence of Protective Associations.

09-02 Jaworski, T. and Wilson, B. Go West Young Man: Self-selection and Endogenous Property Rights.

09-01 Gjerstad, S. Housing Market Price Tier Movements in an Expansion and Collapse.

2008

08-10 Dickhaut, J., Houser, D., Aimone, J., Tila, D. and Johnson, C. High Stakes Behavior with Low Payoffs: Inducing Preferences with Holt-Laury Gambles.

08-09 Stecher, J., Shields, T. and Dickhaut, J. Generating Ambiguity in the Laboratory.

08-08 Stecher, J., Lunawat, R., Pronin, K. and Dickhaut, J. Decision Making and Trade without Probabilities.

08-07 Dickhaut, J., Lungu, O., Smith, V., Xin, B. and Rustichini, A. A Neuronal Mechanism of Choice.

08-06 Anctil, R., Dickhaut, J., Johnson, K., and Kanodia, C. Does Information Transparency Decrease Coordination Failure?

08-05 Tila, D. and Porter, D. Group Prediction in Information Markets With and Without Trading Information and Price Manipulation Incentives.

08-04 Caginalp, G., Hao, L., Porter, D. and Smith, V. Asset Market Reactions to News: An Experimental Study.

08-03 Thomas, C. and Wilson, B. Horizontal Product Differentiation in Auctions and Multilateral Negotiations.

08-02 Oprea, R., Wilson, B. and Zillante, A. War of Attrition: Evidence from a Laboratory Experiment on Market Exit.

08-01 Oprea, R., Porter, D., Hibbert, C., Hanson, R. and Tila, D. Can Manipulators Mislead Prediction Market Observers? 